\title{
Passive Mandibular Border Positions and Their Relationships with Signs and Symptoms of Craniomandibular Disorder A Study of Linear and Angular Measurements
}

\author{
João Gualberto de Cerqueira Luz, Helcio Hiroyuki Uono and Marcos Kazuo Yamamoto
}

(Received 12 September and accepted 31 October 1994)

Key words: mandibular border positions, craniomandibular disorders, stomatognathic physiology

\begin{abstract}
Linear measurements of passive mandibular border positions and angular measurements of passive opening were recorded in a group of patients with craniomandibular disorders. The relationships between signs and symptoms of craniomandibular disorders and abnormal capacity of movement were studied. There was significant association of some signs and symptoms related to the temporomandibular joint and abnormal vertical and horizontal excursions. On the other hand, there was only one relationship between occlusal factors and abnormal passive mandibular border positions.
\end{abstract}

\section{Introduction}

Measurements of mandibular border positions have been purported to indicate the functional status of the stomatognathic system ${ }^{[1,2]}$. Studies of patients with craniomandibular disorders (CMD) have revealed that a reduction of mouth opening should be considered as dysfunction ${ }^{[2,3]}$. Limitations of mandibular border movements may be caused by jaw muscle hyperactivity in CMD cases ${ }^{[4]}$. Other investigators have found no direct connection between a CMD history and maximum jaw opening ${ }^{[5-7]}$. An association between reduced mandibular lateral excursion and the occurrence of signs and symptoms of potential mandibular dysfunction has also been reported ${ }^{[8]}$. Maximum passive mandibular opening has been considered the best measurement of the actual maximum range of motion because it avoids the bias introduced by muscle guarding $^{[9-11]}$. The term passive indicates that the movement is actively performed by the patient up to normal opening, and then forced to a further extent by the hands of the professional.

The purpose of this study was to record the measurements of passive mandibular border positions in a group of CMD patients and to establish possible relationships between the measurements and the presence of signs and symptoms.

\section{Patients and Methods}

The study subjects were 20 patients with CMD examined before the start of treatment. There were 17 women and 3 men, aged 16-27 y (mean $23.3 \mathrm{y}$ ). Individuals were selected if they had a full complement of teeth or had lost no more than three.

The mandibular border positions were registered during passive opening, passive right and left laterotrusion and active protrusion. The mouth opening was measured as the distance in millimeters between the incisal edges of the upper and lower left central incisors. The maximum opening was obtained by including the vertical overbite. The mouth opening was performed by expanding the active opening with the examiner's middle finger and thumb of the non-dominant hand on the mandibular and maxillary incisors. The maximum extent of passive lateral mandibular movement was measured as the distance between the maxillary incisor midline and a vertical line inscribed on the mandibular incisors at the position where the former line falls in occlusion. During laterotrusion, the individual was instructed to move the jaw

Department of Oral and Maxillofacial Surgery, School of Dentistry, University of São Paulo To whom all correspondence should be addressed: Dr. João Gualberto C. Luz, Rua Duarte de Azevedo 284, s. 22 02036-021 São Paulo, SP BRAZIL 
maximally to the right and to the left, while keeping opposing teeth in contact, and by expanding the active laterotrusion with the examiner's middle finger and thumb of the non-dominant hand on the mandibular and maxillary arches.

Finally, the examiner instructed the individual to protrude the mandible, also keeping opposing teeth in contact. In order to measure the protrusion, the horizontal distance between the buccal border of the upper and lower left central incisors was measured. The maximum protrusion was corrected by including the horizontal overbite.

An estimation was also made of the maximum angle of jaw opening using an indirect geometric method $^{[10]}$. The distance (a) between the incisal point and the intercondylar axis was calculated trigonometrically from the mean of the right and left axis-incisal lengths (c), and determining the right angle bisector to the intercondylar distance (b) (Fig. 1A). Using the corrected maximum passive jaw opening including overbite (d), the approximated angle of opening (e) could be calculated (Fig. 1B) using the formula cos angle $e=\left(2 a^{2}-2 d^{2}\right) / 2 a$. The measurement of mandibular border positions was obtained using a rules graduated in millimeters and the mandibular size was obtained using a craniometer (Department of Social Dentistry, School of Dentistry, University of Sao Paulo) (Fig. 2).
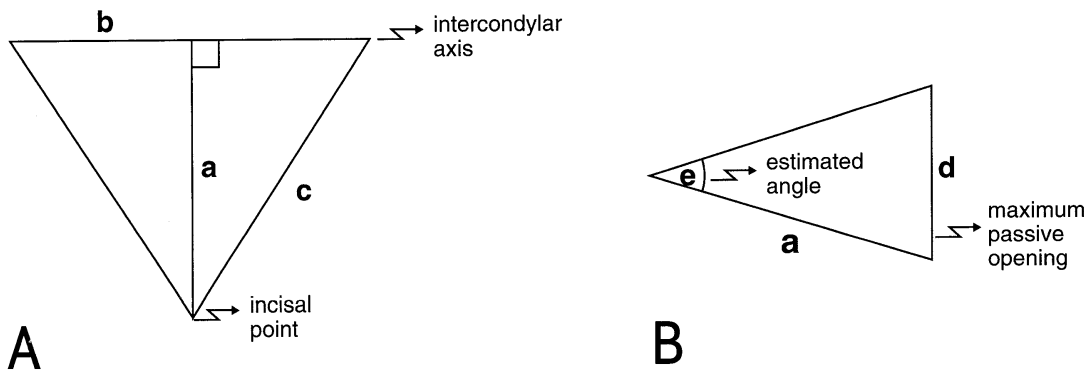

B

Fig.1 Estimation of mandibular length (A) and of maximum angle of jaw opening (B)

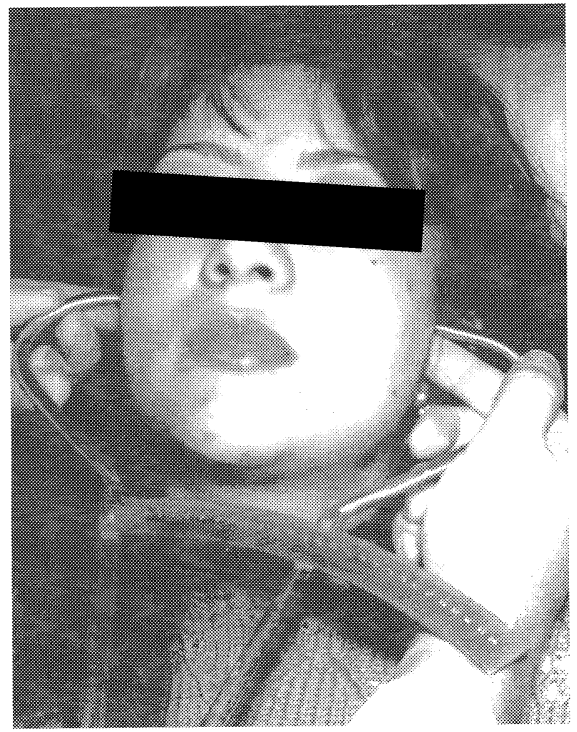

The capacity of the movements was considered abnormal when the measurement was equal to or less than the sample mean minus standard deviation of the mean and equal to or more than the sample mean plus standard deviation of the mean. Chi-squared analysis was used to compare normal and abnormal movement capacities with positive findings of selected signs and symptoms of CMD. The level of significance was $\mathrm{p}<0.05$ in all the statistical analyses.

Fig. 2 Use of craniometer to take intercondylar distance 


\section{Results}

The mean values of maximum mandibular border positions, linear and angular measurements, are shown in Table 1. The relationship between the clinical findings and normal/abnormal mandibular border movements were cross-tabulated. The accepted levels of significance of the chi-squared analyses are shown in Table 2. The location of muscular pain was determined by digital palpation of the anterior, middle and posterior regions of the temporalis, deep and superficial masseter, medial pterygoideus, lateral pterygoideus, sternocleidomastoideus, and posterior cervical muscles. The results of the muscle palpation are summarized in the item "Location of muscular pain".

Table 1 Mean values of mandibular border positions

\begin{tabular}{lrr}
\hline Variable & Mean & S.D. \\
\hline Maximum opening $(\mathrm{mm})$ & 45.9 & 10.9 \\
Right laterotrusion $(\mathrm{mm})$ & 7.2 & 2.2 \\
Left laterotrusion $(\mathrm{mm})$ & 7.8 & 2.3 \\
Maximum protrusion $(\mathrm{mm})$ & 5.8 & 1.8 \\
Opening angle (degree) & 31.3 & 7.9 \\
\hline
\end{tabular}

Table 2 Significance of clinical variables in CMD patients with normal and abnormal mobility of the mandible

\begin{tabular}{|c|c|c|c|c|c|}
\hline \multirow[b]{2}{*}{ Variable } & \multicolumn{5}{|c|}{ Significance } \\
\hline & $\begin{array}{l}\text { Maximum } \\
\text { opening }\end{array}$ & $\begin{array}{l}\text { Right } \\
\text { laterotrusion }\end{array}$ & $\begin{array}{c}\text { Left } \\
\text { laterotrusion }\end{array}$ & $\begin{array}{l}\text { Maximum } \\
\text { protrusion }\end{array}$ & $\begin{array}{l}\text { Opening } \\
\text { angle }\end{array}$ \\
\hline Pain pattern & n. s. & n. s. & $\mathrm{p}<0.05$ & n.s. & n. s. \\
\hline Pain during function & $\mathrm{p}<0.02$ & n. s. & $\mathrm{p}<0.02$ & n.s. & n. s. \\
\hline Pain during emotional stress & n. s. & n. s. & $\mathrm{p}<0.05$ & $\mathrm{p}<0.05$ & n. s. \\
\hline Pain during temperature variation & n. s. & n. s. & n. s. & n.s. & n. s. \\
\hline Location of muscular pain & n. s. & n. s. & n. s. & n. s. & n. s. \\
\hline TMJ pain, lateral aspect & n. s. & n. s. & n. s. & n. s. & n. s. \\
\hline TMJ pain, posterior aspect & n. s. & n. s. & n. s. & n. s. & n. s. \\
\hline Articular sounds & $\mathrm{p}<0.05$ & n. s. & n. s. & n. s. & $\mathrm{p}<0.01$ \\
\hline Angle's classification & n. s. & n. s. & n. s. & n. s. & $\mathrm{p}<0.05$ \\
\hline Balancing contacts & n. s. & n. s. & n. s. & n. s. & n. s. \\
\hline Protrusive contacts & n. s. & n. s. & n. s. & n. s. & n. s. \\
\hline
\end{tabular}

n.s. : Not significant

The analyses showed significant association of mouth-opening capacity with pain during function and articular sounds; left laterotrusion with pain pattern, pain during function and pain during emotional stress; maximum protrusion with pain during emotional stress; opening angle with articular sounds and Angle's classification of occlusion.

\section{Discussion}

A clinical recording method was used for measuring the different maximum mandibular border positions, such as opening, right and left laterotrusion, and protrusion. In addition, an estimation of the angle of jaw opening was made. In measuring all the mandibular border positions, our aim was to study the mandibular capacity of movement ${ }^{[1,12]}$. The angle of jaw opening has been considered the actual vertical 
range of motion ${ }^{[10]}$. The measurements were also corrected for vertical and horizontal overbite, which is a significant variable affecting maximum opening and maximum protrusion ${ }^{[2,10]}$. The passive border positions were obtained by forcible expansion of the mandibular measurements. The use of a passive range for all mandibular border positions was chosen because it has been considered the most accurate form of measurement, avoiding muscle influence ${ }^{[9-11]}$.

The signs and symptoms associated with the temporomandibular joint (TMJ), such as pain pattern, TMJ pain and TMJ sounds, showed few significant relationships with the degree of mandibular opening. TMJ noise is considered to be as a significant sign of $\mathrm{CMD}^{[13]}$. Other investigators have indicated that a correlation exists between signs and symptoms of CMD and limitation of vertical mandibular mobility ${ }^{[2,3]}$. This study, however, seems to support the lack of a direct connection between CMD and maximum jaw opening $^{[5-7]}$. Some signs and symptoms associated with the TMJ demonstrated a relationship with limited jaw excursion in the horizontal plane. This finding supports partially the results of an investigation that revealed an association between reduced mandibular lateral excursion and the occurrence of signs and symptoms of potential mandibular dysfunction ${ }^{[8]}$. In a previous study we reported no significant difference between patients with CMD and symptomatic individuals ${ }^{[1]}$ in measurements of all passive mandibular border positions.

There was only one relationship of Angle's classification of occlusion with the degree of mandibular opening. This finding is in accord with those of other investigators, who found that symptoms of CMD were not related to Angle's classification ${ }^{[14,15]}$. There was no relationship between limitation of mandibular border movements and the existence of a balancing side and protrusive contacts. Our data support the results of investigations that have revealed that signs and symptoms of dysfunction are not correlated with balancing side contacts or with occlusal patterns and interference ${ }^{[16,17]}$. The occlusal factor can thus be considered to be of minor importance within the accepted concept of a multifactorial etiology of mandibular dysfunc$\operatorname{tion}^{[17]}$.

\section{Conclusions}

Within the limitations of this study, the following conclusions were drawn:

1. There was significant association of some signs and symptoms related to the TMJ and abnormal vertical and horizontal excursions;

2. There was only one relationship between occlusal factors and abnormal passive mandibular border positions.

\section{Reference}

[1] Sheppard, I.M. and Sheppard, S.M.: Maximal incisal opening - A diagnostic index, J. Dent. Med., 20, 13-15, 1965

[2 ] Agerberg, G.: Maximal mandibular movements in young men and women, Svensk. Tandlak-t., 67, 8189,1974

[ 3 ] Wedel, A. and Carlsson, G.E.: Analysis of functional disturbances of the masticatory system, $J$. Craniomand. Pract., 2, 350-357, 1984

[4] Correia, F.A.S.: Prevalencia da sintomatologia nas disfuncoes da articulacao temporomandibular e suas relacoes com idade, sexo e perdas dentais, Master's thesis, Universidade de São Paulo, Brazil, 1983

[ 5 ] Rieder, L.E: Maximum mandibular opening in patients with and without a history of TMJ dysfunction, J. Prosth. Dent., 39, 441-446, 1978

[ 6] Maruyama, T., Ishigaki, S., Saito, O., Miyauchi, S. and Akanishi, M.: Clinical study on the jaw opening pathway, J. Osaka Univ. Dent. Sch., 26, 103-112, 1987

[ 7 ] Plunkett, G.A. and West, V.C.: Systemic joint laxity and mandibular range of movement, $J$. Craniomand. Pract., 6, 320-326, 1988

[ 8 ] Balthazar, Y., Ziebert, G. and Donegan, S.: Limited mandibular mobility and potential jaw dysfunc- 
tion, J. Oral Rehab., 14, 569-574, 1987

[9] Graff-Radford, S.B.: Objective measurement of jaw movement: a comparison of two measuring instruments, J. Craniomand. Pract., 3, 240-244, 1985

[10] Pullinger, A.G., Liu, S.P., Low, G. and Tay, D.: Differences between sexes in maximum jaw opening when corrected to body size, J. Oral Rehab., 14, 291-299, 1987

[11] Luz, J.G.C. and Yamamoto, M.K.: Passive mandibular border positions in craniomandibular disorder patients and symptomatic individuals. A comparative study, Ann. Dent., 52, 15-17, 1993

[12] Kang, J.H., Chung, S.C. and Fricton, J.R.: Normal movements of mandible at the mandibular incisor, J. Prosth. Dent., 66, 687-692, 1991

[13] Watt, D.M.: Temporomandibular joint sounds, J. Dent., 8, 119-127, 1980

[14] Greene, C.S. and Marbach, J.J.: Epidemiologic studies of mandibular dysfunction: A critical review, J. Prosth. Dent., 48, 184-190, 1982

[15] Bush, F.M.: Malocclusion, masticatory muscle, and temporomandibular joint tenderness, J. Dent. Res., 64, 129-133, 1985

[16] De Laat, A., Van Streeberghe, D. and Lesaffre, E.: Occlusal relationships and temporomandibular joint dysfunction. Part II: Correlations between occlusal and articular parameters and symptoms of TMJ dysfunction by means of stepwise logistic regression, J. Prosth. Dent., 55, 116-121, 1986

[17] Droukas, B., Lindée, C. and Carlsson, G.E.: Relationship between occlusal factors and signs and symptoms of mandibular dysfunction. A clinical study of 48 dental students, Acta Odontol. Scand., 42, 277-283, 1984 